\title{
Toward an integrated theory of spatial morphology and resilient urban systems
}

\author{
Lars Marcus $^{1}$ and Johan Colding ${ }^{2}$
}

\begin{abstract}
We take the first step in the development of a new field of research with the aim of merging spatial morphology and resilience science. This involves a revisiting and reunderstanding of the meaning of sustainable urban form. We briefly describe the fields of resilience science and spatial morphology. Drawing on a selected set of propositions in both fields, we put urban form in the context of the adaptive renewal cycle, a dynamic framework model used in resilience science to capture the dynamics of complex adaptive systems, of which urban systems are prime examples. We discuss the insights generated in this endeavor, dealing with some key morphological aspects in relation to four key attributes of resilience, i.e., "change," "diversity," "self-organization," and "learning." We discuss and relate these to urban form and other social variables, with special attention paid to the "backloop phase" of the adaptive renewal cycle. We conclude by postulating ways in which resilience thinking could contribute to the development of a new research frontier for addressing designs for resilient urban social-ecological systems, and end by proposing three strategic areas of research in such a field.
\end{abstract}

Key Words: adaptive renewal cycle; resilience theory; space syntax; spatial morphology; urban design

\section{INTRODUCTION}

From planet Earth to spaceship Earth: the sciences of the artificial

In 1967, at the 50th annual convention of the American Planner Association, the engineer, architect, and inventor Buckminster Fuller delivered an address with the title An Operational Manual for Spaceship Earth. The message was that the Earth had become human-dominated to the degree that we should no longer talk about ourselves as living on planet Earth but on spaceship Earth. Consequently, just as any spaceship the Earth was in need of proper human maintenance, hence the need for a manual (Fuller 1969).

Today there is no longer any doubt that we live in a humandominated world. Many of the changes in the biosphere, including the modification of landscapes, loss of biodiversity, and according to most scientists, climate change, are driven by human activities (Folke et al. 2011). According to leading geologists we have as a consequence entered a new geological era, the anthropocene, characterized by profound influence of human activity on fundamental natural processes on Earth (Crutzen 2002). It is also increasingly clear that social and ecological systems truly are interconnected across spatial and temporal scales and could therefore be referred to as social-ecological systems (Berkes and Folke 1998, Berkes et al. 2003).

A contemporary to Fuller is Herbert Simon, whose idea of The Sciences of the Artificial overlaps with Fuller's in many ways (Simon 1969). He made the observation that when living in a world dominated by man-made objects we need "sciences of the artificial" to go along with the sciences of the natural. This idea evolved into design methodology, a field developing knowledge about the creative process behind man-made objects (Alexander 1964, Schön 1983, Cross 2007, Lawson 2006), in which design generally is understood in a broad way as transforming "existing situations into preferred ones" (Simon 1969:55).

The conclusion in brief is that we, first, need to realize that Earth has become a spaceship in the sense that we do not stand outside what we call nature, but are intrinsically part of it. That is, the Earth we inhabit needs to be understood as a social-ecological system (Berkes and Folke 1998). Second, we need to rapidly not only develop knowledge on how this system operates, but also on how we successfully can intervene in it. The critical point is how to translate a growing body of theoretical knowledge into practical intervention. Suffice it to say, we are realizing that we are travelling on a spaceship, but have not yet the means to write its manual.

\section{Merging spatial morphology and resilience science: a new research frontier}

In response to these challenges, we set into communication two theoretical fields that we consider to be particularly well posed for opening up and addressing a new research frontier that we refer to as the "spatial morphology of urban social-ecological systems." These fields are "resilience theory" (Holling 1973) and "spatial morphology" as developed in "space syntax theory" (Hillier and Hanson 1984). Although scholars have dealt with resilience in urban systems (e.g., Pickett et al. 2004, Vale and Campanella 2005, Colding 2007, Alberti 2009, Newman et al. 2009), few, if any, attempts have been made to link urban research to the adaptive renewal cycle developed by Holling (1986). It is this theoretical model and the tentative translation of it into variables of spatial form, thereby making it informative and supportive in design interventions, that is the major focus of this paper. We conclude by presenting three strategic areas that could frame a partly new research field for studying resilience in and of urban systems. 


\section{RESILIENCE THEORY}

The nonlinear dynamics of ecosystems

C. S. Holling (1973) introduced the concept of resilience as a way to understand nonlinear dynamics in natural systems, such as the processes by which ecosystems maintain themselves in the face of natural disturbance, e.g., fires, droughts, floods, etc. Resilience, as applied to integrated systems of people and the natural environment, has three interrelated characteristics: (1) the amount of change the system can undergo and still retain the same controls on function and structure; (2) the degree to which the system is capable of self-organization; and (3) the ability to build and increase the capacity for learning and adaptation (http://www. resalliance.org/).

Holling developed a resilience management approach for ecosystems as a reaction to the "command and control" management that characterizes conventional resource management (Holling and Meffe 1996). Such systems have a strong sector-based focus, often aimed at managing a few target resources, e.g., timber, monoculture crops, a few target fish species, or livestock that are primarily managed for economic output without consideration of the consequences such management has on ecosystem functioning (Regier and Baskerville 1986). A frequent result has been the reduction of the range of natural variation, e.g., diversity, in such systems (Holling and Meffe 1996), leading to increasingly brittle ecosystems that over time lose their capacity to maintain biodiversity and buffer and incorporate natural perturbations (see, e.g., Gunderson et al. 1995, Kasperson et al. 1995, Finlayson and McCay 1998, Gunderson and Holling 2002).

\section{The adaptive renewal cycle}

The adaptive renewal cycle has been proposed as a fundamental framework for understanding complex systems from cells to ecosystems and to societies (Holling and Sanderson 1996). The model highlights the need to focus on what role natural perturbations, e.g., disturbance, have in maintaining productivity in ecosystems and natural resource management systems. In conventional resource management systems such perturbations tend to be blocked out and neglected in favor of growth and conservation.

In the context of the adaptive renewal cycle (Fig. 1), ecosystem behavior can be described as the dynamic interaction among four basic functions: exploitation, conservation, release, and reorganization (Holling 1986). The first two are similar to ecological succession, where progressive change in composition of a community of organisms, e.g., from initial colonization of a bare area (primary succession), or of an already established community (secondary succession), lead to a largely stable climax community (Abercrombie et al. 1992).

Exploitation is represented by those ecosystem processes that are responsible for rapid colonization of disturbed ecosystems characterized by the occurrence of r-strategists that can easily capture accessible resources. This stage is therefore called the $\mathrm{r}-$ stage in the model. Conservation occurs when slow resource accumulation takes place that builds and stores increasingly complex structures. Connectedness and stability increase during the slow sequence from exploitation to conservation and nutrients and biomass is slowly accumulated. Hence this stage is referred to as the $\mathrm{K}$-stage. It may be characterized by late succession species, normally associated with the climax community in ecology textbooks (Clements 1936). The first two stages are often referred to as the fore-loop or S-phase (from $\mathrm{r}$ to $\mathrm{K}$ ) of the cycle.

Fig. 1. The adaptive renewal cycle.

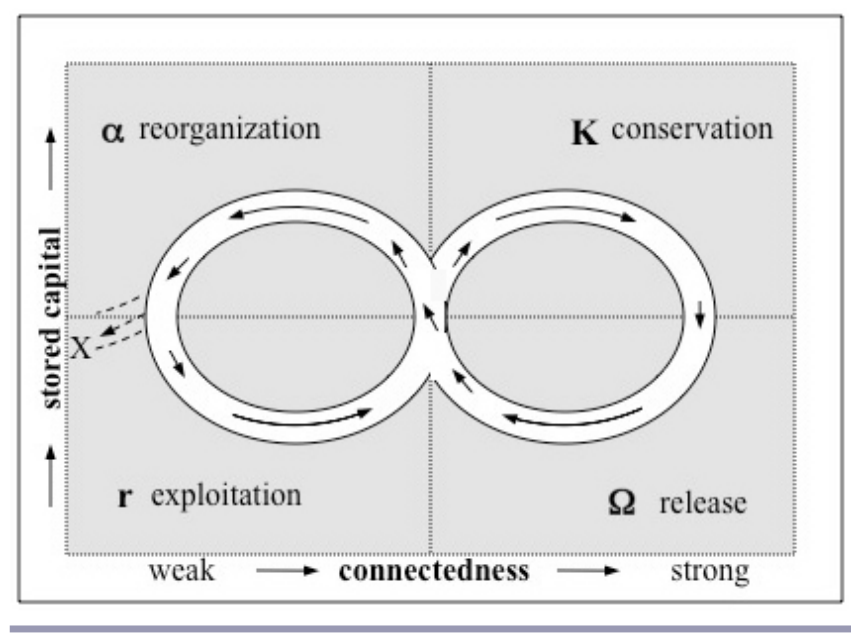

The next function is the release phase, the omega-phase $(\Omega)$. It takes place when the conservation phase has built elaborate and tightly bound structures that have become "overconnected", so that a rapid change is triggered. The system has become brittle. The stored biomass is then suddenly released and the tight organization lost. The abrupt destruction is created internally but caused by an external disturbance, i.e., fire, disease, or grazing pressure. This process of change both destroys and releases opportunity for the fourth stage, reorganization. In this phase, called the alpha-phase $(\alpha)$, released materials are mobilized to become available for the next exploitation phase.

The stability and productivity of the system is determined by the slow exploitation and conservation sequence. Resilience is determined by the effectiveness of the last two functions, often referred to as the back-loop phase. Hence, natural perturbations are an important part of ecosystem development and evolution and are crucial for ecosystem resilience and integrity. If they are blocked out, the ecosystem will become even more overconnected, and thereby invite even larger-scale perturbations over time with the risk of massive and widespread destruction.

Implicit in the notion of resilience is that ecosystems have critical thresholds for how much disturbance they can buffer. A threshold is the point where a system "flips" from one equilibrium state to another (Holling et al. 1998). Hence, only if back-loop conditions are right, the next exploitation phase can begin. If the right conditions are lacking, an ecosystem may "flip" and shift into another stability domain in which it no longer will generate the functions and services it previously produced. The X in Figure 1 marks this possibility. Examples of such shifts in ecosystems are when a degraded forest turns into a dessert, a savannah turns into shrub land (Walker 1993), or when a functional coral reef turns into an algae-dominated reef (Nyström et al. 2000).

\section{The adaptive cycle and social systems}

Renewal for an ecosystem can simply mean the endless repetition of the same functions that it previously provided; however, for 
human systems this would mean that humanity was tied to a determinism that would repeat the lessons of history in perpetuity without considering options for human will, learning, or history (Holling and Sanderson 1996). Hence, for social systems the backloop phase of the adaptive cycle rather signifies situations that facilitate innovation and restructuring, the kind of processes that signal social transformation. For a social system, whether economic or cultural, what is termed natural capital could therefore be considered as "infrastructure capital," "levels of organizational complexity," "skills," "networks of human relationships," and "mutual trust" or "standard operating techniques" that are incrementally refined and improved during the progression from the r- to K-phase (Holling and Sanderson 1996:65).

Holling borrowed much of his thinking from the AustrianAmerican economist Joseph Schumpeter when developing the adaptive cycle, and especially Schumpeter's idea of "creative destruction," which he adapted and popularized from Karl Marx as a theory for economic innovation. ${ }^{[1]}$ The important difference to that of ecosystems is that the power and potential force of transformation operates from within social systems. Adaptive cycles are also nested in a hierarchy across time and space, i.e., a panarchy, which helps explain how adaptive systems can generate novel recombinations for brief moments in time, which are tested during longer periods of capital accumulation and storage. These windows of innovation open briefly, but do not trigger cascading instabilities of the whole because of the stabilizing nature of nested hierarchies, e.g., panarchies (Gunderson and Holling 2002).

\section{Urban systems and the adaptive cycle}

Early on, Holling and Goldberg (1971) pointed out the remarkable similarities between ecological and urban systems, including their functioning as interdependent systems, their dependence on a succession of historical events, their spatial linkages, and their nonlinear structure, with both systems appearing to have considerable internal resilience within a certain domain of stability. Moreover, they viewed a city not as a homogenous structure, but rather as "a spatial mosaic of social, economic, and ecological variables that are connected by a variety of physical and social dispersal processes" (Holling and Goldberg 1971:227). However, few linkages have been made between urban systems and the adaptive cycle to broaden understanding of urban dynamics and the critical properties that may confer resilience in urban systems.

For a start, we have placed city-growth in the context of the adaptive cycle in Figure 2. Although the figure is an oversimplification, it illuminates that cities mainly grow from the bottom up, and that their size and shape follow well-defined scaling laws that result from intense competition for space (Batty 2008). We have also added smaller adaptive cycles or, "creativedestruction" cycles as borrowed from Schumpeter's notion of major innovations that drive growth in progressive cycles (Schumpeter 1950). These cycles are in the figure associated with major technological innovations of the industrial revolutions, i.e., the steam engine, the electric motor and the combustion engine, and information technology, each of which has given rise to periods of new development blocks (e.g., Schön 2000, Enflo et al. 2007, Ernstson et al. 2010). ${ }^{[2]}$
Fig. 2. Urban growth in the context of the adaptive cycle.

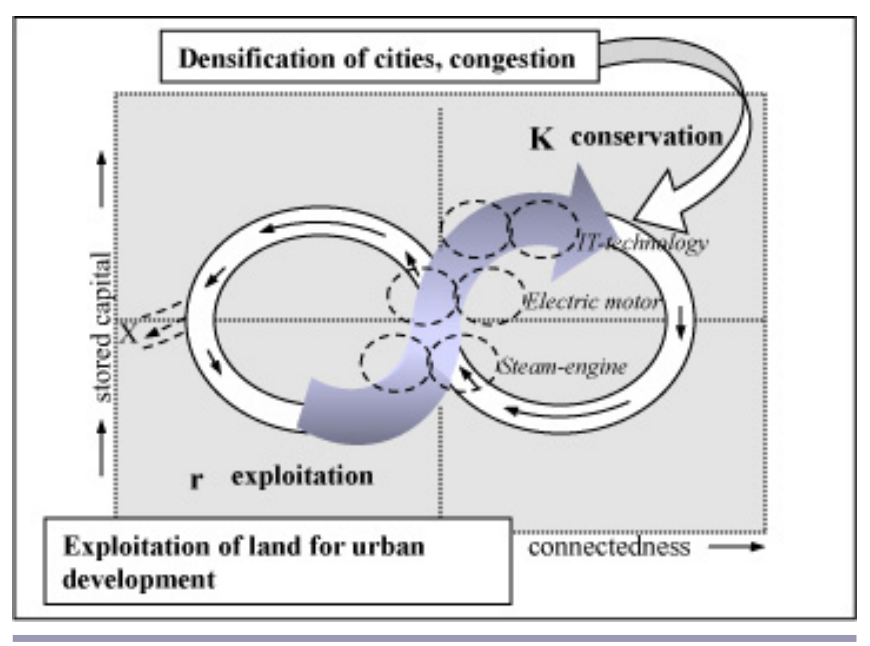

Similar to species competing for resources during ecosystem growth, and with late-successional organisms progressively taking control as the ecosystem matures, a few industrial sectors take the lead and interact with others in a complementary way during each evolutionary growth cycle. It is, however, important to realize that the technologies of the industrial revolutions removed the constraints imposed by limitations in the environment, permitting development to take place as if there were no environmental limitations, what Harvey (1990) calls the first great time-space compression, or as put by Holling and Goldberg (1971:227):

The only constraints were placed by economic needs, hence the great emphasis on economic growth. The result, therefore, is an urban system with many of the characteristics of an early stage in an ecological succession. The system is changing rapidly in time and is not closed. Without any apparent limitation, water and air are considered as free goods to receive, at no cost ...

As recognized by Batty (2008), it is a simple consequence of competition and limits on resources that there are far fewer large cities than small, but the processes that drive agglomeration and clustering in small cities are similar to those in large cities. As a city grows it becomes increasingly denser, where limitation of space and resources ultimately creates congestion. As a way to cope with densification, urban sprawl, identified as America's leading land-use problem (Freilich 1999), follows, resulting in the spread of urban congestion into adjoining suburbs and rural areas, and to dispersed automobile-dependent land-use patterns.

Moreover, the same nonlinear, discontinuous structural properties noted in ecological systems apply to urban systems. For example, thresholds exist with regard to city size and below given thresholds certain activities do not occur in cities (Krugman 1991). For instance, suburban areas and smaller cities generally do not have larger museums, operas, symphonies, or a great variety of cinemas and restaurants. These activities appear to occur above certain population, or density-thresholds ${ }^{[3]}$ and notions such as agglomeration and per capita servicing costs are all nonlinear relationships with respect to city size (Holling and 
Fig. 3. The axial map: a network representation of urban spatial form, constructed by the least amount of straight lines that cover all public open space, where the axial line represents a space that is possible to visually overlook and physically access for an experiencing person in the street.

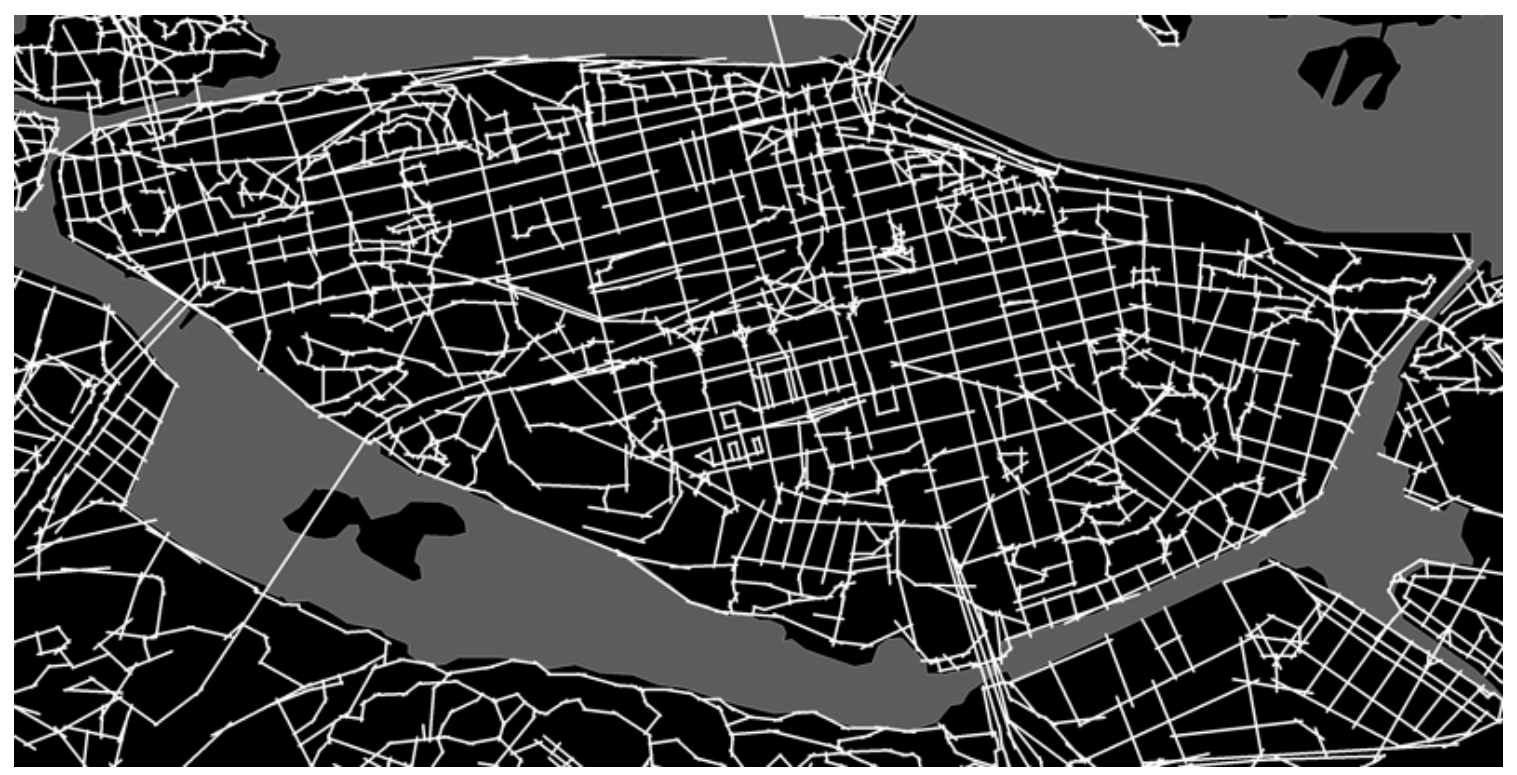

Goldberg 1971). Similarly, certain species may thrive in urban systems until a critical threshold of urban densification (Hale et al. 2012). Hence, city designs that promote resilience need to encapsulate the attractiveness that cities hold for humans in terms of providing cultural diversity, socioeconomic advantages, as well as capacity for dealing with the environmental trade-offs ${ }^{[4]}$ they impose in their growth and expansion.

\section{SPATIAL MORPHOLOGY}

Spatial form as an intermediate system for urban design In response to the first challenge posed in the introduction, resilience theory presents a theoretical basis for understanding social and natural systems as nonlinear processes that can be applied as an explanatory framework for urban social-ecological systems. The second challenge concerns the development of knowledge that can inform intervention in such systems, through urban governance, planning, and design. For this we need to acknowledge that such intervention is never conducted directly to the natural and social processes that constitute urban systems but via particular media such as "discourse," "institutions," and "spatial form." We develop the argument by focusing on urban design and its particular medium "urban space" as structured and shaped by built form, keeping in mind that such interventions are part of a nested hierarchy of other interventions, e.g., urban governance and planning with many interconnections, overlaps, and backloops.

There is a long history of urban modeling aimed at analyzing the spatial component in different urban processes (e.g., Wilson 2000), the origin of which is often identified to be the analyses of land uses and land values by von Thünen (1826). With the development of modern computers, this tradition has been augmented in a dramatic way, both in the form of geographic information systems (e.g., Longley et al. 2011), but also more advanced forms of spatial modeling, e.g., cellular automata and agent-based modeling (e.g. Batty 2013). However, urban modeling has generally been dominated by analysis of aggregated levels of urban systems (Batty 2005). This is in part due to the difficulties of gathering fine scale data, but more importantly, to the difficulties of relevant modeling of urban space at a finer scale. There is therefore agreement that knowledge on how to model, what can be called "the cognitive level of urban space," that is, the level where "people in the street" experience the city, is underdeveloped. Urban geographers (Talen 2003), spatial analysts (Kwan et al. 2003), and urban morphologists (Hillier 1996) independently point out the lack of knowledge on this scale of urban space. Current knowledge development, mainly based on aggregated data and low spatial resolution, is therefore deemed unsatisfactory for theoretical advancement of the field (Batty 2008).

Space syntax: the configurative analysis of urban space

A promising approach for increasing our understanding of the cognitive level of urban space is "space syntax," in which an analytical approach is taken to the cognitive level of urban space, specifically aiming to develop knowledge that can support architectural and urban design (Hillier and Hanson 1984, Hillier 1996). This direction of urban modeling has developed a rich set of analytical measures on the cognitive scale of urban space. Of fundamental importance is the development of the "axial map," which is a network representation of urban space using graph theory (Fig. 3), constructed from the point of view of a cognitive subject, i.e., an experiencing and acting human being. The axial map is made up of the least amount of straight lines that cover all accessible open space in the area of analysis, where each straight line (here called "axial line") in the map represents an urban space that is possible to visually overlook and physically access (Fig. 3). Thus, the axial map constitutes a network, defined 
Fig. 4. Integration (or closeness centrality), calculated in an axial map (fat lines represent high integration and thin lines represents low.

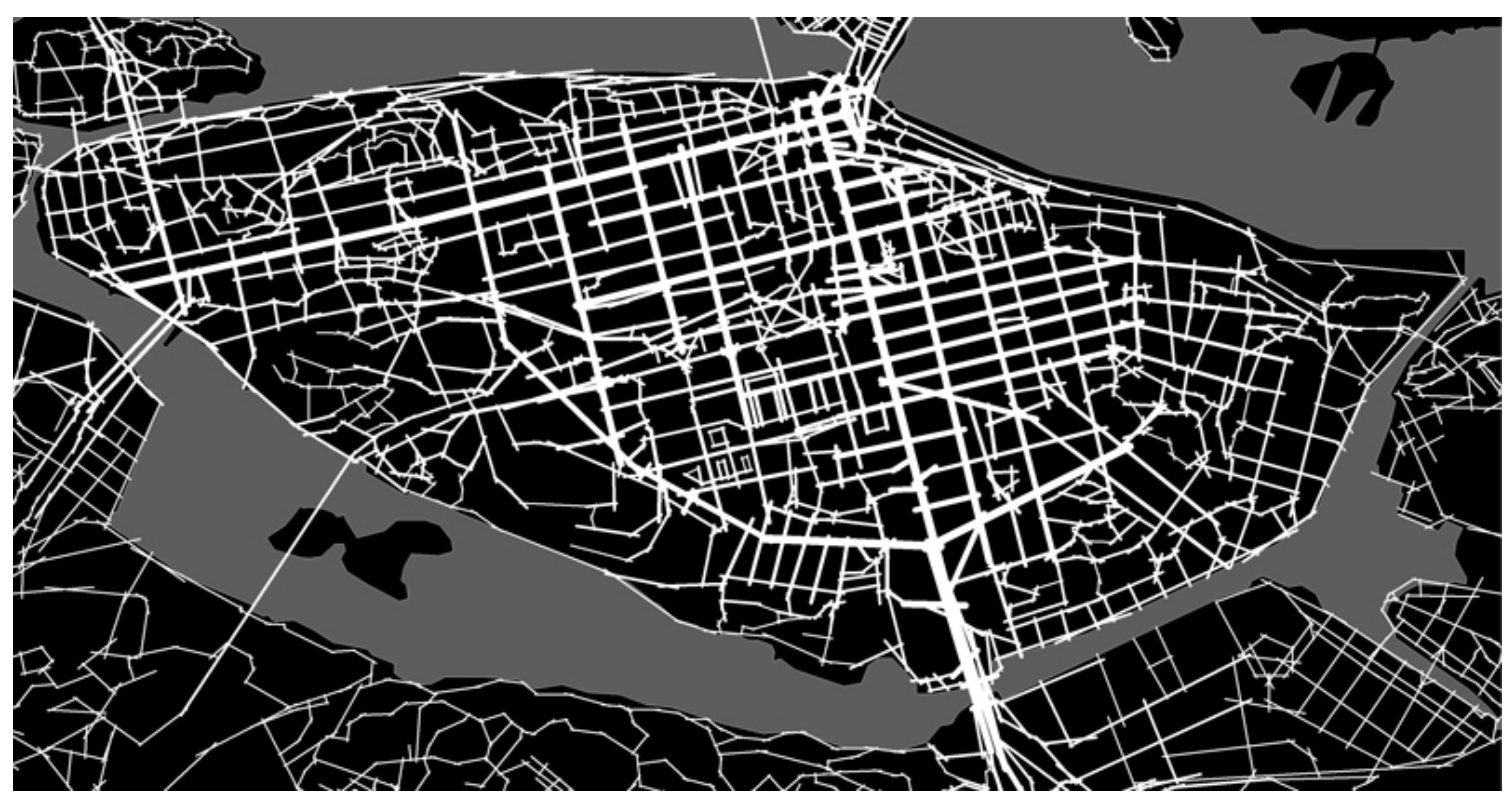

on the cognitive scale, of all accessible spaces in the urban area it represents, in which different properties of this network are possible to measure. Typically, one can measure what in network theory is called "closeness centrality" (Newman 2010), but which in space syntax is called "integration."

Based on this type of modeling, a long series of studies around the world have found strong correlations between spatial form and pedestrian movement, that is, a most generic aspect of urban space use (Hillier et al. 1993, Hillier and Iida 2005). Moreover, a large body of research (e.g. Koch et al. 2009, Greene et al. 2012) has found correlations between urban form and other urban phenomena, in which movement works as the intermediary. For example, it is not surprising to find that streets that are highly integrated in the street system and therefore attract a lot of movement also become prominent locations for retail. This has been confirmed in many studies (e.g., Bernow and Ståhle 2011, Scoppa 2012). Taking this a step further, it also seems likely that such streets in the long run may gather higher rents for the letting of floor-space, and this has been confirmed (e.g., Desyllas 2000, Netzell 2010).

Research aiming to expand space syntax research into a wider field of spatial morphology has been undertaken under the heading "spatial capital" (Marcus 2010). In this framework, three fundamental geometric variables of spatial form and techniques for their measurements have been identified and tested. These are similar to other measures of the built environment, for example the 3D concept (Cervero and Kockelman 1997), but more interestingly in the current context, also basic morphological variables in landscape ecology (Alberti 2009). However, they differ from both in that they aim to capture properties of the built environment on the scale of human perception and cognition. The first is "distance," i.e., the possibility of structuring the street network in cities whereby buildings and public spaces, not least green areas, are set in particular relations to each other, which creates variations in accessibility between different locations in an urban system (Fig. 4). Second, there is "density," i.e., the possibility to expand urban space through built form by adding floor space on top of each other, in short, the typical activity of constructing multifloor buildings in certain locations (Fig. 5).

Third is "diversity," i.e., the possibility of enhancing urban space by dividing it into additional spaces; this is the typical planning activity of dividing urban land into different plots and parcels for different uses/owners, which is an intrinsic part of the continuous process of defining and redefining property rights (Webster 2002). By dividing land into few or many spaces, i.e., plots or parcels, we are likely to influence the amount of agents (owners and/or ownership regimes) in an urban area and, by extension, potentially also influence the diversity of activities in the area (Fig. 6).

In the framework of "spatial capital," distance, density, and diversity are understood as measures of three fundamental variables of spatial form with distinct relations to generic aspects of human use of urban space: in principle, spatial distance with accessibility to human activity, spatial density with amount of human activity, and spatial diversity with differentiation of human activity. Hence, this provides the possibility to talk about these as measures of variations in "spatial capital" in the urban landscape, that is, measures of cities as a multitude of locations with distinctly different spatial potentials for human activity (Marcus 2010).

\section{INTEGRATING THE TWO: AN OUTLINE OF A SPATIAL} MORPHOLOGY OF RESILIENCE

From the brief descriptions of the two fields described herein, it is clear that what we are looking for is not only the spatial means to understand and intervene in social-ecological systems but more 
Fig. 5. Variations in accessibility to built floor space within $1000 \mathrm{~m}$, following the street network, calculated from each parcel (light grey represents high accessibility and dark grey low).

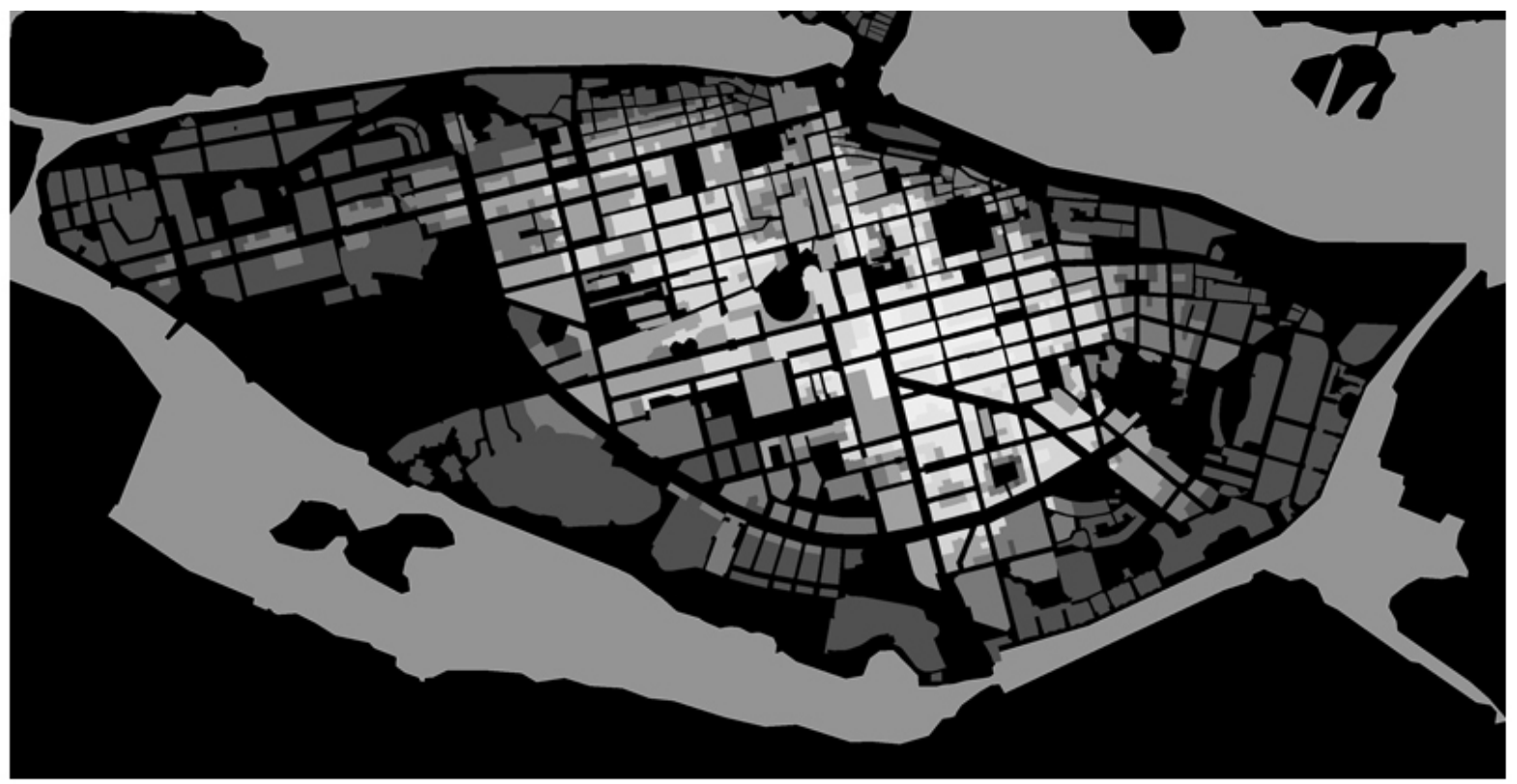

Fig. 6. Variations in accessibility to parcels within $1000 \mathrm{~m}$, following the street network, calculated from each parcel (light grey represents high accessibility and dark grey low).

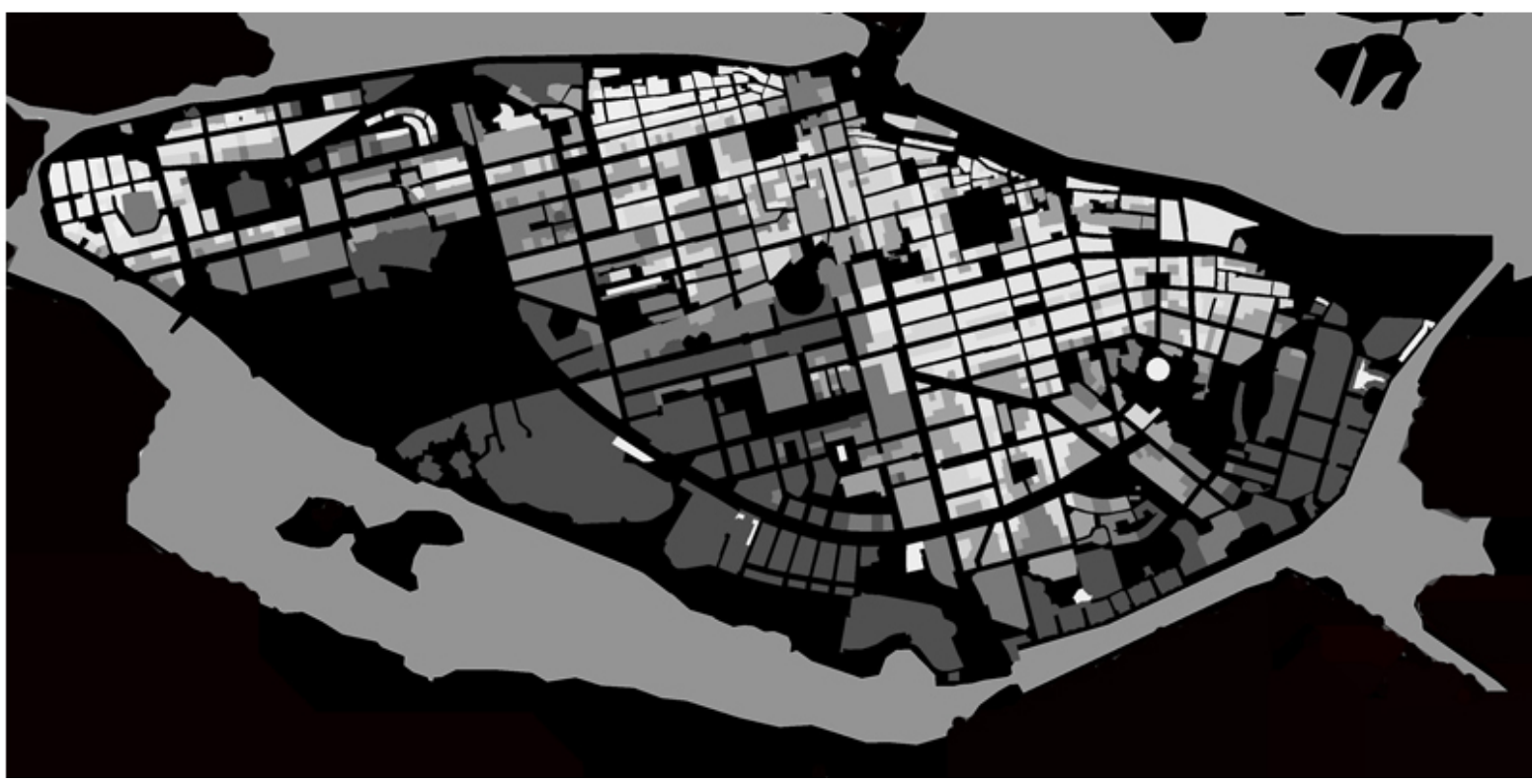

particularly, resilient social-ecological systems. This is the reason why we first need to identify the morphological properties of resilience to develop a spatial morphology of urban socialecological systems. For this, we now turn attention to four critical attributes that appear fundamental for building resilience in complex adaptive systems.
These attributes have been identified and synthesized through a number of empirical case studies on long-enduring socialecological systems (Berkes and Folke 1998, Berkes et al. 2003). They include "change" (or "disturbance"), "diversity," "selforganization," and "knowledge" (or "learning"; Fig. 7). 
Fig. 7. Change (disturbance), learning, diversity, and selforganization as critical attributes of resilient systems. Adopted from Folke et al. (2003) and modified by Barthel et al. (2013).

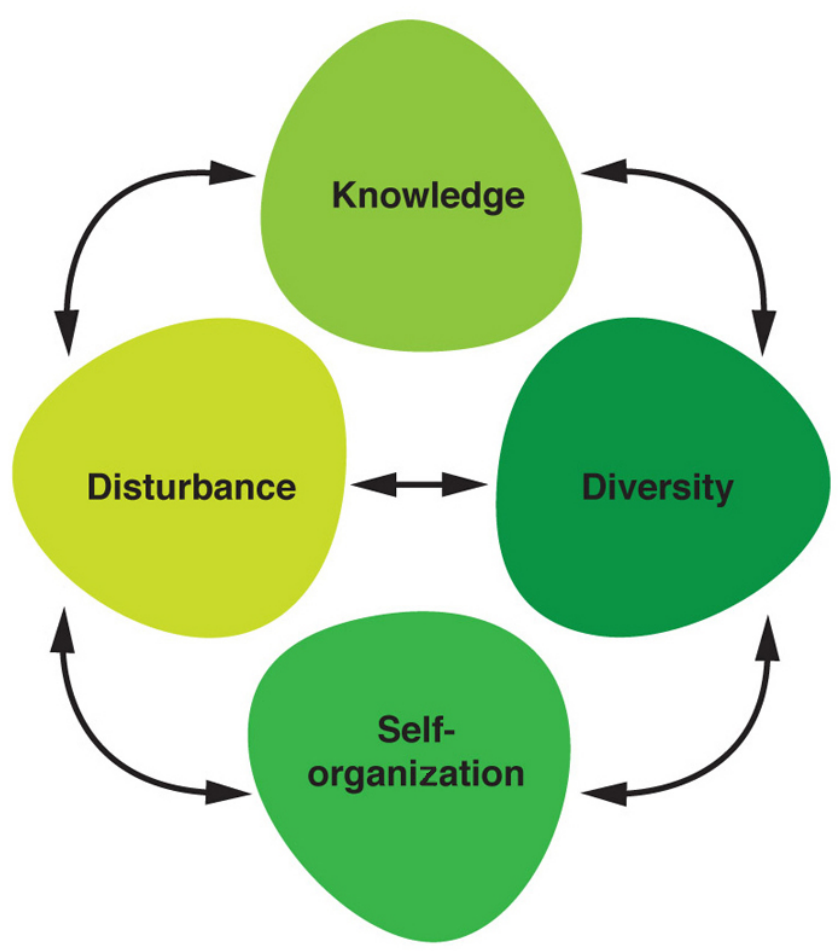

Change and diversity: the conditioning attributes of resilient systems

In resilience thinking "change," or "disturbance," is an inherent characteristic of all complex adaptive systems (Levin 1999). Change, in this sense, is not regarded as a threat but necessary for renewal and novelty in a system. Since Connell (1978) launched the "intermediate disturbance hypothesis" in ecology, empirical evidence demonstrates that moderate frequencies and intensities of disturbance foster species richness in ecosystems (Colding et al. 2003a). Framed in the context of the adaptive cycle, change or disturbance is considered key for ecosystem renewal to take place (Holling et al. 1998). In degraded ecosystems, i.e., those with reduced resilience, a natural disturbance may lead to the system moving into another functional state, from one stability to another, i.e., "flipping." Hence, the scale and magnitude of disturbance together with the inherent resilience of the system determines to what degree it is capable of self-repairing (Nyström et al. 2000).

In the adaptive cycle, environmental change is not regarded as continuous and gradual, but rather as episodic, because natural capital, e.g., biomass or nutrients, accumulates slowly, and then suddenly is released by disturbances like storms, droughts, flooding, or the arrival of invading species. Analogously, change in social systems appears also to be episodic, like periods of economic recession, rapid technological innovation, and even social revolution, although the underlying causes may have accumulated over long time periods. However, cycles of "creative destruction" take place during rather long time periods (see e.g., Schön 2000).

In the spatial terminology developed above, we can in general terms say that change (disturbance) can either come from within an urban system, for instance a particular city, or externally from this system. External change (disturbance or innovation) is related to the degree an urban system is connected or accessible to surrounding systems, i.e., other cities or green areas, also at quite great distances, and the potential to hereby receive input of different kinds, be it in the form of information, people, or biotic components. Responding to change from within, on the other hand, has to do with the connectedness or accessibility of different parts within the system so that information, people, and biotic components from these parts can access each other and construct new constellations and thereby potentially give rise to change and innovation. In either case, allowing for change and thereby creating resilience through adaptability and learning seems in spatial terms intrinsically determined by the variable of accessibility at different scales.

Such variations in accessibility in an urban system can be illustrated on the detailed cognitive level earlier discussed, using space syntax (Fig. 4). We can then detect distinct varieties in relative accessibility, that is, accessibility from a particular spatial unit (in the axial map represented by the axial line) to all other spatial units in the system, on a most detailed level. In common parlance we could speak of each spatial unit's mean "closeness" to all other spatial units in the system. We can then identify how certain spatial units, or groups of such units, clearly are more accessible (closer) to the rest of the system than others, which implies that they, in principle, also are more accessible to disturbance or change.

In principle this could also be true for biotic components, but then we would need to adapt the spatial model to include spatial connections among local ecosystems and not only the urban system as is the case here. Such attempts have been made (Marcus et al. 2013), integrating concepts in urban ecology (Alberti 2009), however, further research is needed. Interpreted in terms of resilience, such greater internal accessibility would, in principle, create greater opportunity for renewal and change and strengthen the system's ability to adapt.

"Diversity" is another conditioning attribute for building resilience in complex adaptive systems (Berkes et al. 2003). Diversity spreads risks by generating redundancy, creating buffers, and opening up multiple strategies from which humans can learn in situations when uncertainty is high. In addition to functioning as insurance, diversity also plays a vital role in the reorganization and renewal processes of systems that have been disturbed (Holling and Sanderson 1996, Berkes et al. 2003). Diversity is thus seen as a key feature for dealing with change in productive ways, with selforganization and the capacity for learning and adaptation constituting important attributes for managing diversity in constructive ways (Fig. 7). The important role that diversity holds has been described for many systems, e.g., genetic, human engineered, complex adaptive, ecological, and governance systems (Low et al. 2003).

In the spatial terminology we want to introduce here, diversity is directly connected to the concept of "spatial diversity," that is, the presence of multiple spaces, here defined as the degree of land division into parcels or patches of land, which can harbor, support, 
and develop differences in human activity, and in extension also in ecosystems. The idea is simply that for diversity to exist and develop, one entity needs a space distinct from another, both as a means to conserve its difference but also as a means to develop it further.

This can be integrated in the accessibility analysis above by weighing each street segment with the amount of parcels or patches of land adjoining it, which transforms the pure accessibility analysis into an analysis of accessible parcels or patches (Fig. 6). The same thing can be done when measuring density. We then transform the analysis into one of accessible density. Of major importance in both cases is the fact that by using the distance measures particularly developed in Space Syntax to capture the cognitive level of urban space, we also transform the density and diversity measures into measurements of these variables as accessibility on the cognitive level of urban space (Ståhle et al. 2005).

Keeping in mind the principal level of the present argument, we can still conclude that we thus have created a model of the variations in spatial conditions for both change (disturbance) and diversity in the urban system, which in resilience terms seems critical for the ability to spread risk, create buffers, and facilitate reorganization in phases of renewal. What we see are the contours of a generic spatial system that, on the one hand, can vary in its degree of distinct spaces that can carry difference and, on the other hand, depending on the structure of the particular system, can also vary in the degree that these are made accessible to each other.

\section{Box 1: The Bow and Battersea examples}

Social anthropologist Sandra Wallman describes similar system properties as discussed here in terms of open/heterogeneous and closed/homogenous urban systems (Wallman 2003). Drawing upon extensive field work (Wallman et al. 1982, Wallman 1984, 1985) of two London boroughs in the 1980s, i.e., Battersea in south London and Bow in east London, with similar diverse mixes of culture, Wallman found that the local system's capacity to survive times of drastic change varies with its degrees of open/ closedness, and that the more closed and homogenous the local structure is, the less flexible it is to survive economic and social disruptions. This was expressed in such different urban dimensions as industrial structure, industrial type, employment opportunity, travel to work patterns, travel facilities, labor movement, housing options, exclusive access, criteria for membership, and political traditions (Wallman 2003). For instance, when it comes to industrial structure, Battersea is made up of small firms and industries, whereas Bow is made up only of three big industries, providing a narrow range of jobs with failure in any of them being catastrophic. Likewise, Battersea has access to all London and beyond through public transport; by contrast, public transport in Bow is limited. Moreover, housing options are heterogeneous in Battersea with a mix of private and public rental properties, whereas in Bow $94 \%$ of housing is publically owned.

Most interestingly, it is "proximity to diversity" that is the critical crux in Wallman's argument (Zanoni and Janssens 2009), suggesting that open/heterogeneous urban systems that facilitate access to diversity hold a better chance to survive different types of socioeconomic crises than closed/homogenous systems. This is a direct parallel to what in spatial terms are expressed as "accessibility to diversity" (Marcus 2010), the critical difference being that Zanoni and Janssens speak of the urban system as a social system whereas Marcus speaks of the urban system as a spatial system. The former represents actual lived urban systems whereas the latter represents a potential instrument for intervention in the lived urban system through design. When Wallman (2003) further explains "proximity to diversity" as a function of adaptable networks and that different urban subsystems are defined by the nature of relationships holding them together and their potential for communication among these relationships depends on the style and scope of connections within the system and among its parts, she does everything but spell out this design potential.

\section{Self-organization and memory: the operative attributes of resilient systems}

The potential of urban design could more explicitly be expressed in terms of two operative attributes of resilient systems that we now turn to. The capacity to respond to and shape change in productive ways is a function of "self-organization" (Folke et al. 2003). For example, social systems that have the ability to respond to change and reorganize in constructive ways are likely to have flexible institutions, i.e., rules and norms, that allow for adaptation to changing circumstances (Ostrom 1990), and a social organization that allows for knowledge exchange among different stakeholders and actors so that appropriate responses to changing conditions are facilitated and cultural inertia avoided (Colding et al. 2003b).

This can be described in spatial terms using our generic model above. Depending on how the spaces that carry differences, e.g., parcels or patches, such as different human activities, are connected to each other, these differences are to various degrees able to reconfigure when facing change. For example, shops typically respond to new market demands by reconfiguring in new geographic clusters, but the potential for such adaption is limited by the opportunities given by the spatial structure of the urban system. This pertains both to the supply of locations with the particular degree of accessibility suitable for a particular type of shop, as well as the spatial diversity, that is the resolution in land division into parcels, suitable for such a type of shop.

Thus, the degree to which an urban spatial system allows for selforganization is highly influenced by its particular configuration of accessibility and land division. We can speak of a variety in what we want to call a "spatial redundancy" in the system, where a higher degree of redundancy is created by increasing the accessibility in the system as well as increasing its capacity to carry differences through land division into plots and parcels. For example, it has been shown in both social and natural systems that division of land into discrete plots or parcels (in cities) or patches (in nature) can increase both social and biological diversity at the landscape level (Marcus 2001, Colding 2007). This in turn can be argued, keeping in mind the principal nature of the current discussion, to promote the ability of social and natural 
systems to self-organize, especially when this is coupled with high internal accessibility as discussed above, e.g., through street networks or biological corridors.

Finally, the capacity in a system for "learning" or to carry "knowledge" is another essential attribute for building resilience (Folke et al. 2003). For human systems learning implies knowledge in many forms but on a more general level, including ecological systems, we use the idea of learning in the sense of "memory," that is, the ability of the system to retrieve lost information after disturbance, damage, or loss (Folke et al. 2003). Critical here is the notion of "spatial resilience," for example, the renewal of damaged ecosystems from pockets of unharmed habitats and species after disturbance (Nyström and Folke 2001, Cumming 2011).

In spatial terms this again points to the fundamental role of our generic model of spatial connections and discrete spaces, where the more segregated spaces can work as pockets of memory for survival in crises and from which the system can be retrieved if the right connections are present. In extension, the specific configuration typical for a particular ecological or social system, or a combination of the two, can be reflected and manifested in the concrete configuration of the urban spatial system, which thereby can be said to carry memory and even knowledge about this particular system. In contrast, if such spatial support of the system is not allowed it will be more difficult to "remember." Hence, creating different concrete spatial configurations in the system through urban design becomes a form of "writing" that carries memory of the particular properties of the social or ecological function the system is designed for. In a resilience framework we can come to a general conclusion, saying that a high degree of spatial redundancy, as defined above, promotes self-organization but decreases the degree of memory written into the system, while a low degree of redundancy works in the opposite way.

\section{Tentative interpretations in terms of the adaptive renewal cycle}

Interpreting this in the framework of the adaptive renewal cycle, one can argue, that low redundancy is important for conserving an urban system in the growth phase, i.e., from $r$ to $\mathrm{K}$, in the same way that stabilizing forces are important in maintaining productivity and biogeochemical cycles in an ecological system (Holling and Sanderson 1996). On the other hand, high redundancy is important in maintaining diversity, resilience, and opportunity, because low redundancy in this sense is less apt to deal with change or disturbance in creative ways precisely because diversity is reduced. As the adaptive cycle suggests, competition in the growth phase leads to fewer entities, i.e., firms, property rights, or bureaucracies, dominating and controlling the system as economic productivity increases; hence, diversity and selforganization are reduced.

It is therefore important to point out how the adaptive renewal cycle is a model of temporal processes, whereas the spatial model proposed above is a model of spatial structure. Typical for space is that it can carry many processes simultaneously; many trajectories parallel in time (Massey 2005). Therefore, our proposed spatial model can, in principle, carry different sequences of the adaptive renewal cycle at the same time. This ability to carry parallel processes is of course fundamental for cities.
A possible conclusion from this is, for instance, that to retain some self-organizing capacity and thereby promote resilience in a city growth-phase, urban planners should avoid scaling up the property structure, because a more fine-grained land division seems to increase the ability to self-organize and survive in times of crises. In other terms, planners that assume that existing systems in cities constitute "the natural order" of things, should be aware of the fact that as cities mature, self-organizing capacity is likely to be reduced in urban subsystems. This suggests that increased knowledge on the properties that confer resilience in urban systems hold a real potential to counteract undesirable development trajectories, and that urban design has a critical role to play for building resilience in urban systems.

\section{Box 2: The Södermalm example}

The notions of high spatial redundancy (meaning high accessibility and high resolution in land division) and low spatial redundancy (meaning low accessibility and low resolution in land division) have been empirically tested as generic design strategies in an extensive study in Stockholm (Marcus 2000). In that study, areas designed with a high degree of spatial redundancy correlated strongly with both high amounts of pedestrians moving in public space and high amounts of business types present in its buildings; attributes typically corresponded to lively urban areas with a lot of retail, restaurants, and general urban buzz. Areas designed with a low degree of spatial redundancy, on the other hand, correlated with the opposite, low amounts of movement in streets and a limited range of economic activity, i.e., attributes of the typically quiet residential urban area with a slower pace.

These findings correspond with attempts to apply space syntax theory in more general interpretations of the relation between the spatial form of cities and the evolution of societies (e.g., Hillier and Vaughan 2007, Hillier 2009). A fundamental and empirically supported idea here is that urban street grids, on a generic level, often are constituted by a "foreground network" that distributes high accessibility throughout the urban system, which can be interpreted to facilitate socioeconomic exchange and innovation, and a "background network" that in patches throughout the system creates secluded and undisturbed spaces, which similarly can be interpreted to facilitate socio-cultural continuity and reproduction (Hillier 2009; Fig. 8). The difference is that the Södermalm study, just as the model proposed in this article, adds a measurement of the variations in spatial potential for diversity in cities, by analyzing varieties in land division.

Because of its particular design, urban space can thus be described as being able to, at varying degrees, simultaneously support parallel but different processes: on the one hand, processes of innovation and, on the other hand, processes of sustenance. To directly interpret variations in spatial redundancy, as defined here, as coupled with variations in self-organization and memory in social and ecological systems, as discussed in resilience theory, obviously is a simplification. However, our aim here is to demonstrate that urban spatial form, in principle, can be the object of design with direct influence on such properties and thereby that it also is possible to adjust such properties to enhance the resilience of such a system. 
Fig. 8. London within the M25 with its approximation of the deformed wheel, visualizing also the concept of the foreground and background network. Image (C) Bill Hillier and Laura Vaughan, with permission, originally published in the journal Progress in Planning, 2007.

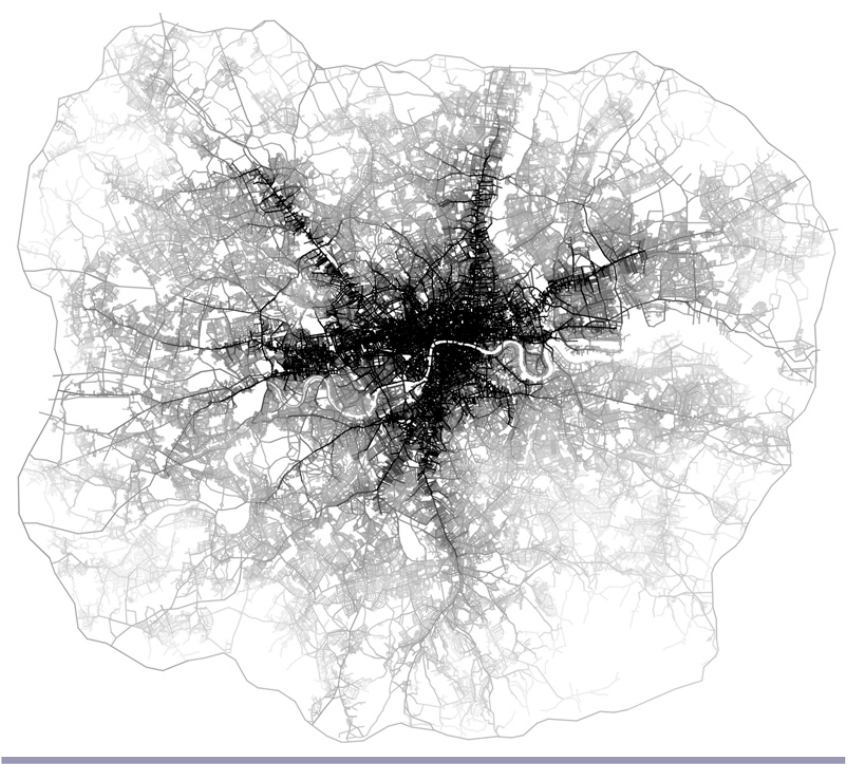

\section{CITIES AS RESILIENT SYSTEMS: THE NEED FOR A SPATIAL MORPHOLOGY}

We have turned attention to how urban systems and more specifically their spatial form can be understood in terms of a resilience framework. Although our point of departure has been to put urban systems in the context of the adaptive renewal cycle, we have opened up new ways of analyzing urban systems by merging key notions and insights in spatial morphology with that of resilience science. As described herein, the attributes that may confer resilience in complex adaptive systems have been shown, in principle, to have distinctive spatial dimensions that can be translated into a generic network model for resilient urban systems, which by extension also creates the possibility for informed intervention in urban systems by way of design.

To be able to proceed and develop such a field for studying urban systems that confer resilience, we need to pioneer a new analytical framework in the field of spatial morphology. More specifically, we see three primary and strategic areas that could frame such a research field. First is research in the area of spatial morphology, where we need to integrate the conceptualization of spatial form in urban ecology with that in urban design for more powerful exploration of attributes that build resilience in urban systems. Second is research in the area of institutions, hinted upon in this article, by way of exploring the institutional embedding that can support resilient spatial form. Third, we need to explore new discursive systems that may challenge many of the fundamental concepts and assumptions that currently frame the urban sustainability discourse, and which in turn can provide a more scientifically informed foundation for institutional and spatial systems supporting urban social-ecological systems. In conclusion, we believe this could be a major contribution in the development of an operational manual for spaceship Earth, keeping in mind the lessons of humility learned since the days of Buckminster Fuller.

${ }^{[1]}$ Schumpeter (1950) viewed socioeconomic transformations in such a way that market forces controlled the r-phase of innovation; institutional hierarchies, monopolism, and social rigidity controlled the $\mathrm{K}$-phase of consolidation; forces of "creative destruction" triggered the $\Omega$-phase; and technological innovation determined the source for the transition at the $\alpha$-phase (Holling and Sanderson, 1996).

${ }^{[2]}$ For example, the second industrial revolution, from the $1890 \mathrm{~s}$ up until the late 20th century, had far-reaching repercussions on growth and society (Enflo et al. 2007), and this in turn had consequences for urban growth and form. In the midst of this revolution was the breakthrough of the electrical motor and the combustion engine that liberated economic growth from a set of constraints that had become more inhibiting with industrial expansion during the 19th century (Enflo et al. 2007). These constraints concerned the supply and price of energy, e.g., coal, the localization of industry, and the organization of the industrial work process, so that modern economic growth and industrialization became a more encompassing social adventure (Enflo et al. 2007).

${ }^{[3]}$ For instance, a city of 500,000 residents has more than five times the variety of activities a city of 100,000 has (Holling and Goldberg 1971).

[4] With regards to the latter, cities claim ecosystem support, including waste absorption, that sometimes is 500-1000 times larger than their own area (Folke et al. 1997). Moreover, although half the world population resides in urban settings, urban systems claim an unproportionally high degree of ecosystem services, and account for as much as $78 \%$ of all carbon emissions (Grimm et al. 2008).

Responses to this article can be read online at: http://www.ecologyandsociety.org/issues/responses. $\mathrm{php} / 6939$

\section{Acknowledgments:}

This research is part of the Urban Form-project. Johan Colding's and Lars Marcus's research has been funded through support and grants received from the Swedish Research Council for Environment, Agricultural Sciences and Spatial Planning (FORMAS). Thanks also to Mistra (the Foundation for Strategic Environmental Research) for support to the Stockholm Resilience Centre.

\section{LITERATURE CITED}

Abercrombie, N., M. Hickman, M. L. Johnson, and M. Thain. 1992. The Penguin dictionary of biology. Eighth edition. Penguin Books, London, UK.

Alberti, M. 2009. Advances in urban ecology: integrating humans and ecological processes in urban ecosystems. Springer, New York, New York, USA. 
Alexander, C. 1964. Notes on the synthesis of form. Harvard University Press, Cambridge, Massachusetts, USA.

Barthel, S., J. Colding, S. Grahn, H. Erixon, H. Ernstson, C. Kärsten, L. Marcus, and J. Torsvall. 2013. Principles of socialecological urbanism. TRITA-ARK-2013:3, KTH, Stockholm.

Batty. M. 2005. Cities and complexity: understanding cities with cellular automata, agent based models and fractals. MIT Press, Cambridge, Massachusetts, USA.

Batty, M. 2008. The size, scale, and shape of cities. Science 319:769-771 http://dx.doi.org/10.1126/science.1151419

Batty, M. 2013. The new science of cities. MIT Press, Cambridge, Massachusetts, USA.

Berkes, F., and C. Folke. 1998. Linking social and ecological systems: management practices and social mechanisms for building resilience. Cambridge University Press, Cambridge, UK.

Berkes, F., J. Colding, and C. Folke. 2003. Navigating socialecological systems: building resilience for complexity and change. Cambridge University Press, Cambridge, UK. http://dx.doi. org/10.1017/CBO9780511541957

Bernow, R., and A, Ståhle. 2011. Värdering av stadskvaliteter: Sammanfattning av metod och resultat. Stockholms stad, Stockholms Läns Landsting, Haninge kommun, Lidingö stad, Nacka kommun, Stockholm, Sweden.

Cervero, R., and K. Kockelman. 1997. Travel demand and the 3D:s: density, diversity, and design. Transportation Research Part D: Transport and Environment. 2(3):199-219. http://dx.doi. org/10.1016/S1361-9209(97)00009-6

Clements, F. E. 1936. Nature and structure of the climax. Journal of Ecology 24:252-284. http://dx.doi.org/10.2307/2256278

Colding, J. 2001. Local institutions, biological conservation and management of ecosystem dynamics. Dissertation. Department of Systems Ecology, Stockholm University, Stockholm, Sweden.

Colding, J. 2007. 'Ecological land-use complementation' for building resilience in urban ecosystems. Landscape and Urban Planning 81:46-55 http://dx.doi.org/10.1016/j.landurbplan.2006.10.016

Colding, J., C. Folke, and T. Elmqvist. 2003a. Social institutions in ecosystem management and biodiversity conservation. Journal of Tropical Ecology 44:25-41

Colding, J., T. Elmqvist, and P. Olsson. 2003b. Living with disturbance: building resilience in social-ecological systems. Pages 163-185 in F. Berkes, J. Colding, and C. Folke, editors. Navigating social-ecological systems: building resilience for complexity and change. Cambridge University Press, Cambridge, UK.

Connell, J. H. 1978. Diversity in tropical rain forests and coral reefs. Science 199:1302-1310. http://dx.doi.org/10.1126/

science.199.4335.1302

Cross, N. 2007. Designerly ways of knowing. Birkhäuser, Basel, Switzerland.

Crutzen, P. J. 2002. Geology of mankind. Nature 415:23. http:// dx.doi.org/10.1038/415023a
Cumming, G. S. 2011. Spatial resilience: integrating landscape ecology, resilience, and sustainability. Landscape Ecology 26:899-909. http://dx.doi.org/10.1007/s10980-011-9623-1

Desyllas, J. 2000. The relationship between urban street configuration and office rent patters in Berlin. Dissertation, University College London, London, UK.

Enflo, K., A. Kander, and L. Schön. 2007. Identifying development blocks - a new methodology. Journal of Evolutionary Economics 18:57-76. http://dx.doi.org/10.1007/ s00191-007-0070-8

Ernstson, H., S. E. van der Leeuw, C. L. Redman, D. J. Meffert, G. Davis, C. Alfsen, and T. Elmqvist. 2010. Urban transitions: on urban resilience and human-dominated ecosystems. Ambio 39 (8):531-545. http://dx.doi.org/10.1007/s13280-010-0081-9

Finlayson, A. C., and B. J. McCay. 1998. Crossing the threshold of ecosystem resilience: the extinction of the commercial cod. Pages 311-338 in F. Berkes and C. Folke, editors. Linking social and ecological systems: institutional learning for resilience. Cambridge University Press, Cambridge, UK.

Folke, C., J. Colding, and F. Berkes. 2003. Synthesis: building resilience and adaptive capacity in social-ecological systems. Pages 352-387 in F. Berkes, J. Colding, and C. Folke, editors. Navigating social-ecological systems: building resilience for complexity and change. Cambridge University Press, Cambridge, UK. http://dx.doi.org/10.1017/CBO9780511541957.020

Folke, C., Å. Jansson, J. Larsson, and R. Costanza. 1997. Ecosystem appropriation by cities Ambio 26:167-172.

Folke, C., Å. Jansson, J. Rockström, P. Olsson, S. Carpenter, F. S. Chapin III, A.-S. Crépin, G. Daily, K. Danell, J. Ebbesson, T. Elmqvist, V. Galaz, F. Moberg, M. Nilsson, H. Österblom, E. Ostrom, Å. Persson, G. Peterson, S. Polasky, W. Steffen, B. Walker, and F. Westley. 2011. Reconnecting to the biosphere. Ambio 40:719-738. http://dx.doi.org/10.1007/s13280-011-0184-y

Freilich, R. H. 1999. From sprawl to smart growth: successful legal, planning, and environmental systems. Section of State and Local Government Law, American Bar Association, Chicago, Illinois, USA.

Fuller, B. 1969. Operating manual for Spaceship Earth. Simon and Schuster, New York, New York by permission of Southern Illinois University Press, Carbondale, Illinois, USA.

Greene, M., J. Reyes, and A. Castro. 2012. Proceedings of the 7th International Space Syntax Symposium. Pontefica Universidad Catholica de Chile, Santiago de Chile, Chile.

Grimm, N. B., S. H. Faeth, N. E. Golubiewski, C. L. Redman, J. Wu, X. Bai, and J. M. Briggs. 2008. Global change and the ecology of cities. Science 319:756-760. http://dx.doi.org/10.1126/ $\underline{\text { science. } 1150195}$

Gunderson, L. H., and C. S. Holling. 2002. Panarchy: understanding transformations in human and natural systems. Island Press, Washington, D.C., USA.

Gunderson, L. H., C. S. Holling, and S. S. Light. 1995. Barriers and bridges to the renewal of ecosystems and institutions. Columbia University Press, New York, New York, USA. 
Hale, J. D., A. J. Fairbrass, T. J. Matthews, J. P. Sadler. 2012. Habitat composition and connectivity predicts bat presence and activity at foraging sites in a large UK conurbation. PLOS ONE 7(3):e33300. http://dx.doi.org/10.1371/journal.pone.0033300

Harvey, D. 1990. The condition of postmodernity: an enquiry into the origins of cultural change. Cambridge University Press, Cambridge, Massachusetts, USA.

Hillier, B. 1996. Space is the machine. Cambridge University Press, London, UK.

Hillier, B. 2009. Spatial sustainability in cities: organic patterns and sustainable forms. Pages 16-35 in D. Koch, L. Marcus, and J. Steen, editors. Proceedings of the 7th International Space Syntax Symposium. Trita-Ark-Research publication 2009:1, Royal Institute of Technology, Stockholm, Sweden.

Hillier, B., and J. Hanson. 1984. The social logic of space. Cambridge University Press, Cambridge, UK. http://dx.doi. org/10.1017/CBO9780511597237

Hillier, B., and S. Iida. 2005 Network and psychological effects in urban movement. Pages 475-490 in A. G. Cohn and D. M. Mark, editors. Spatial information theory: lecture notes in computer science 3693. Springer Verlag, Berlin, Germany. http://dx.doi. org/10.1007/11556114 30

Hillier, B., A. Penn, J. Hanson, T. Grajewski, and J. Xu. 1993. Natural movement: or, configuration and attraction in urban pedestrian movement. Environment and Planning B: Planning and Design 20:29-66. http://dx.doi.org/10.1068/b200029

Hillier, B., and Vaughan, L. 2007. The city as one thing. Progress in Planning 67:205-230.

Holling, C. S. 1973. Resilience and stability of ecological systems. Annual Review of Ecology and Systematics 4:1-23. http://dx.doi. org/10.1146/annurev.es.04.110173.000245

Holling, C. S. 1986. Resilience of ecosystems: local surprise and global change. Pages 292-317 in W. C. Clark and R. E. Munn, editors. Sustainable development of the biosphere. Cambridge University Press, Cambridge, UK.

Holling, C. S., F. Berkes, and C. Folke. 1998. Science, sustainability and resource management. Pages 342-362 in F. Berkes, and C. Folke, editors. Linking social and ecological systems: institutional learning for resilience. Cambridge University Press, Cambridge, UK.

Holling, C. S., and M. A. Goldberg. 1971. Ecology and planning. Journal of the American Institute of Planners 37:221-230. http:// dx.doi.org/10.1080/01944367108977962

Holling, C. S., and G. K. Meffe. 1996. Command and control and the pathology of natural resource management. Biodiversity conservation 10:328-37.

Holling, C. S., and S. Sanderson. 1996. Dynamics of (dis) harmony in ecological and social systems. Pages 57-86 in $\mathrm{S}$. Hanna, C. Folke, and K. G. Mäler, editors. Rights to nature: ecological, economic, cultural, and political principles of institutions for the environment. Island Press, Washington, D.C., USA.
Kasperson, J. X., R. E. Kasperson, and B. L. Turner. 1995. Regions at risk: comparisons of threatened environments. United Nations University Press, New York, New York, USA.

Koch, D., L. Marcus, and J. Steen. 2009. Proceedings of the 7th International Space Syntax Symposium. Trita-Ark-Research publication 2009:1, Royal Institute of Technology, Stockholm, Sweden.

Krugman, P. 1991. Increasing returns and economic geography. Journal of Political Economy 99:483-499. http://dx.doi. org/10.1086/261763

Kwan, M.-P., A. T. Murray, M. E. O'Kelly, and M. Tiefelsdorf. 2003. Recent advances in accessibility research: representation, methodology and applications. Geographical Systems 5:129-138. http://dx.doi.org/10.1007/s101090300107

Lawson, B. 2006. How designers think. Architectural Press, Oxford, UK.

Levin, S. 1999. Fragile dominion: complexity and the commons. Perseus Books, Reading, Massachusetts, USA.

Longley, P., M. Goodchild, D. Maguire, and D. Rhind. 2011. Geographic information systems and science. J. Wiley and Sons, London, UK.

Low, B., E. Ostrom, C. Simon, and J. Wilson. 2003. Redundancy and diversity: do they influence optimal management. Pages 83-114 in F. Berkes, J. Colding, and C. Folke, editors. Navigating social-ecological systems: building resilience for complexity and change. Cambridge University Press, Cambridge, UK. http://dx. doi.org/10.1017/CBO9780511541957.007.

Marcus, L. 2000. Architectural knowledge and urban form: the functional performance of architectural urbanity. Thesis. TRITAARK 2000:2, Royal Institute of Technology, Stockholm, Sweden.

Marcus, L. 2001. The impact of land-division on long-term occupation: the possibility of such a thing as natural occupation. Pages 38.1-38.11 in J. Peponis, editor. Proceedings of the 3rd International Space Syntax Symposium. Georgia Institute of Technology, Atlanta, Georgia, USA.

Marcus, L. 2010. Spatial capital: a proposal for an extension of space syntax into a more general urban morphology. Journal of Space Syntax 1(1).

Marcus, L., M. Berghauser Pont, and Å. Gren. 2013. Can spatial form support urban ecosystem services - representing patches and connectivity zones for bees using space syntax methodology. In Proceedings of the 9th International Space Syntax Symposium. Sejong University Press, Seoul, South Korea.

Massey, D. 2005. For space. Sage, London, UK.

Netzell, O. 2010. Essays on lease and property valuation. Dissertation. TRITA-FOB 2010:4, Royal Institute of Technology, Stockholm, Sweden.

Newman, M. E. J. 2010. Networks - an introduction. Oxford University Press, Oxford, UK.

Newman, P., T. Beatley, and H. Boyer. 2009. Resilient cities: responding to peak oil and climate change. Island Press, Washington, D.C., USA. 
Nyström, M., and C. Folke. 2001. Spatial resilience of coral reefs. Ecosystems 4(5):406-417. http://dx.doi.org/10.1007/s10021-001-0019$\mathrm{y}$

Nyström, M., C. Folke, and F. Moberg. 2000. Coral reef disturbance and resilience in a human-dominated environment. Trends in Ecology \& Evolution 15:413-417. http://dx.doi. org/10.1016/S0169-5347(00)01948-0

Ostrom, E. 1990. Governing the commons: the evolution of institutions for collective action. Cambridge University Press, Cambridge, UK. http://dx.doi.org/10.1017/CBO9780511807763

Pickett, S. T. A., M. L. Cadenasso, and J. M. Grove. 2004. Resilient cities: meaning, models, and metaphor for integrating the ecological, socio-economic, and planning realms. Landscape and Urban Planning 69:369-384. http://dx.doi.org/10.1016/j.

landurbplan.2003.10.035

Regier, H. A., and G. L. Baskerville. 1986. Sustainable development of regional ecosystems degraded by exploitive development. Pages 75-103 in W. C. Clark and R. E. Munn, editors. Sustainable development of the biosphere. Cambridge University Press, Cambridge, UK.

Schön, D. 1983. The reflective practitioner. Basic Books, New York, New York, USA.

Schön, L. 2000. En modern svensk ekonomisk historia: tillväxt och omvandling under två sekel. SNS Förlag, Stockholm, Sweden.

Schumpeter, J. A. 1950. Capitalism, socialism and democracy. Harper and Row, New York, New York, USA.

Scoppa, M. 2012. Towards a theory of distributed attraction: the effects of street network configuration upon the distribution of retail in the City of Buenos Aires. Dissertation. The School of Architecture, Georgia Institute of Technology, Atlanta, Georgia, USA.

Simon, H. 1969. The sciences of the artificial. MIT Press, Cambridge, Massachusetts, USA.

Ståhle, A., L. Marcus, and A. Karlström. 2005. Place syntax - a space syntax approach to accessibility. Pages 131-139 in Proceedings of the 5th International Space Syntax Symposium. Technische Universität Delft, Delft, Netherlands.

Talen, E. 2003. Measuring urbanism: issues in smart growth research. Journal of Urban Design 8:195-215. http://dx.doi. org/10.1080/1357480032000155141

von Thünen, J. H. 1826. Der isolierte Staat in Beziehung auf Landwirtschaft und Nationalökonomie. Gustav Fischer, Stuttgart, Germany.

Vale, L. J., and T. J. Campanella. 2005. The resilient city: how modern cities recover from disaster. Oxford University Press, Oxford, UK.

Walker, B. H. 1993. Rangeland ecology: understanding and managing change. Ambio 22:80-87.

Wallman, S. 1984. Eight London households. Tavistock, London, UK.

Wallman, S. 1985. Success and failure in the inner city. Town \& Country Planning 54:12.
Wallman, S. 2003. The diversity of diversity: implications of the form and process of localised urban systems. Fondazione ENI Enrico Mattei Working Papers 76.2003. http://dx.doi.org/10.2139/ $\underline{\text { ssrn.464686 }}$

Wallman, S., I. H. Buchanan, Y. Dhooge, J. I. Gershuny, B. A. Kosmin, and M. Wann. 1982. Living in south London: perspectives on Battersea 1871-1981. Gower, Aldershot, UK.

Webster, C. J. 2002. Property rights and the public realm: gates, green-belts and gemeinshaft. Environment and Planning B: Planning and Design 29:397-412. http://dx.doi.org/10.1068/ $\underline{b 2755 r}$

Wilson, A. 2000. Complex spatial systems: the modelling foundations of urban and regional analysis. Prentice Hall, Harlow, $\mathrm{UK}$.

Zanoni, P., and M. Janssens. 2009. Sustainable divercities. Pages 3-25 in M. Janssens, D. Pinelli, D. C. Reyman, and S. Wallman, editors. Sustainable cities: diversity, economic growth and social cohesion, Edward Elgar, Cheltenham, UK. 